\title{
Robust Performance Analysis on Dynamic Control of Unmanned Aerial Vehicle System Using Bode Plot
}

\author{
Hteik Tin Cho Nyunt ${ }^{1}$, Thanda Win', Hla Myo Tun ${ }^{3,}$ * \\ ${ }^{1}$ Department of Electronic Engineering, Government Technical High School (Shwe Pyi Thar), Yangon Region, Republic of the Union of \\ Myanmar \\ ${ }^{2}$ Department of Electronic Engineering, West Yangon Technological University, Yangon Region, Republic of the Union of Myanmar \\ ${ }^{3}$ Department of Electronic Engineering, Yangon Technological University, Yangon Region, Republic of the Union of Myanmar
}

Email address:

ecdepartment.ytu@gmail.com (H. M. Tun)

\section{To cite this article:}

Hteik Tin Cho Nyunt, Thanda Win, Hla Myo Tun. Robust Performance Analysis on Dynamic Control of Unmanned Aerial Vehicle System Using Bode Plot. American Journal of Astronomy and Astrophysics. Vol. 7, No. 4, 2019, pp. 48-53. doi: 10.11648/j.ajaa.20190704.11

Received: October 19, 2019; Accepted: November 14, 2019; Published: November 25, 2019

\begin{abstract}
The paper focuses on the robust performance analysis on dynamic control of unmanned aerial vehicle system with numerical computation. The objectives of this work are to find the appropriate solution for robust stability problems for dynamic control of unmanned aerial vehicle (UAV) system which is critical challenge in the space technology. The background of the theoretical work on digital control system is very important to study the problem of dynamic control system at present. The idea behind the control system stability analysis on digital technology is very important candidate in space technology. The specific purpose on analyzing the performance of dynamic of digital control system for space technology is solved in this paper. The mathematical model of target system is mentioned and analyzed based on the classical control method with digital technology. The related work for modeling of the control system is mentioned and expressed the detailed background for the analysis. The simulation results confirm that the proposed system met the robust performance for digital control of UAV system for reality. The analysis has been carried out based on feedback control system stability for dynamic system as well. The simulation results for stability analysis have been carried out by using MATLAB programming languages.
\end{abstract}

Keywords: Robust Performance, Dynamic Control, Unmanned Aerial Vehicle, Numerical Analysis, MATLAB

\section{Introduction}

An unmanned aircraft system is just that - a system. It must always be considered as such. The system comprises a number of sub-systems which include the aircraft (often referred to as a UAV or unmanned air vehicle), its payloads, the control station(s) (and, often, other remote stations), aircraft launch and recovery sub-systems where applicable, support subsystems, communication sub-systems, transport sub-systems, etc. It must also be considered as part of a local or global air transport/aviation environment with its rules, regulations and disciplines. UAS usually have the same elements as systems based upon manned aircraft, but with the airborne element, i.e. the aircraft being designed from its conception to be operated without an aircrew aboard. The aircrew (as a sub-system), with its interfaces with the aircraft controls and its habitation is replaced by an electronic intelligence and control subsystem.
The other elements, i.e. launch, landing, recovery, communication, support, etc. have their equivalents in both manned and unmanned systems [1-2].

Unmanned aircraft must not be confused with model aircraft or with 'drones', as is often done by the media. A radio-controlled model aircraft is used only for sport and must remain within sight of the operator. The operator is usually limited to instructing the aircraft to climb or descend and to turn to the left or to the right. A drone aircraft will be required to fly out of sight of the operator, but has zero intelligence, merely being launched into a pre-programmed mission on a pre-programmed course and a return to base. It does not communicate and the results of the mission, e.g. photographs, are usually not obtained from it until it is recovered at base. A UAV, on the other hand, will have some greater or lesser degree of 'automatic intelligence'. It will be able to communicate with its controller and to return payload data such as electro-optic or thermal TV images, together 
with its primary state information - position, airspeed, heading and altitude. It will also transmit information as to its condition, which is often referred to as 'housekeeping data', covering aspects such as the amount of fuel it has, temperatures of components, e.g. engines or electronics. If a fault occurs in any of the sub-systems or components, the UAV may be designed automatically to take corrective action and/or alert its operator to the event. In the event, for example, that the radio communication between the operator and the UAV is broken, then the UAV may be programmed to search for the radio beam and re-establish contact or to switch to a different radio frequency band if the radio-link is duplexed. A more 'intelligent' UAV may have further program which enable it to respond in an 'if that happens, do this' manner. For some systems, attempts are being made to implement on-board decision-making capability using artificial intelligence in order to provide it with autonomy of operation, as distinct from automatic decision making [3-4].

UAVs are being used in research and development works in the aeronautical field. For test purposes, the use of UAV as small-scale replicas of projected civil or military designs of manned aircraft enables airborne testing to be carried out, under realistic conditions, more cheaply and with fewer hazards. Testing subsequent modifications can also be effected more cheaply and more quickly than for a larger manned aircraft, and without any need for changes to aircrew accommodation or operation. Novel configurations may be used to advantage for the UAV. These configurations may not be suitable for containing an aircrew. The modern battlefield has increasingly progressed towards the use of automated systems and remotely controlled devices to perform a variety of missions. From surveillance to weapons delivery and bomb damage assessment, the human operator is being removed from the direct danger of a hostile environment and placed in a position of evaluating data received via $\mathrm{RF}$ or fiber optic link. The direct and obvious benefits of such an arrangement are the reduced risk to the operator.and the reduced cost of the unmanned sensor platform as compared to traditional manned platforms. The state-of-the-art technology in unmanned aerial vehicle development has demonstrated the capability of flight out to ranges of $500 \mathrm{~nm}$ and endurances exceeding 24 hours. Combined with the ability to carry a variety of sensor suites, these platforms represent the future in airborne data acquisition for both military and civilian applications [5].

The rest of the paper is organized as follows. Section II presents the background theory and mathematical model of the robust control system. Section III mentions the analysis and discussions. Section IV concludes the proposed system.

\section{Background Theory and Mathematical Model}

The mathematical model for robust system of UAV has been developed in this section. There have been two portions to model the mathematical expressions of UAV system is discussed in this portion [6-8].

\subsection{Robust Stability}

Robust stability can be investigated in the frequency domain, using the Nyquist stability criterion. Consider a Nyquist contour for the nominal open-loop system $\mathrm{G}_{\mathrm{m}}(\mathrm{j} \omega) C(j \omega)$ with the model uncertainty given by

$$
\mathrm{G}(\mathrm{s})=\mathrm{G}_{\mathrm{m}}(\mathrm{s})+\mathrm{l}_{\mathrm{a}}(\mathrm{s})
$$

or multiplicative uncertainty $1_{\mathrm{m}}(\mathrm{s})$

$$
\mathrm{G}(\mathrm{s})=\left(1+\mathrm{l}_{\mathrm{m}}(\mathrm{s})\right) \mathrm{G}_{\mathrm{m}}(\mathrm{s})
$$

Equation (1) and (2) gives

$$
\mathrm{l}_{\mathrm{a}}(\mathrm{s})=\mathrm{l}_{\mathrm{m}}(\mathrm{s}) \mathrm{G}_{\mathrm{m}}(\mathrm{s})
$$

where $G_{m}(s)$ is nominal plant and $l_{a}(s)$ is additive uncertainty.

Block diagram representations of additive and multiplicative model uncertainty are shown in Figure 1. Structured uncertainty relates to parametric variations in the plant dynamics, i.e. uncertain variations in coefficients in plant differential equations [9-10].

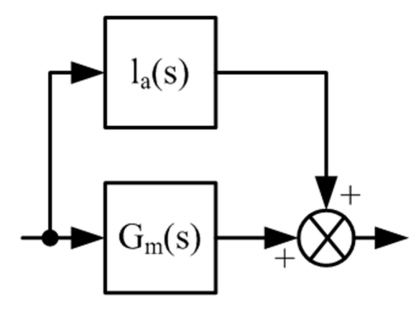

(a) Additive Mode Uncertainty

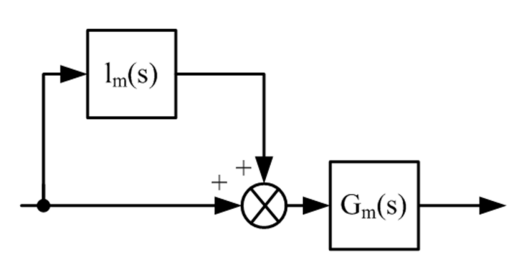

(b) Multiplicative Uncertainty

Figure 1. Additive and Multiplicative Model Uncertainty.

Let $\overline{l_{a}}(\omega)$ be the bound of additive uncertainty and therefore be the radius of a disk superimposed upon the nominal Nyquist contour. This means that $G(j \omega)$ lies within a family of plants $\pi(\mathrm{G}(j \omega) \in \pi$ described by the disk, defined mathematically as

$$
\pi=\left\{G:\left|G(j \omega)-G_{m}(j \omega)\right| \leq \bar{l}_{a}(\omega)\right\}
$$

and therefore

$$
\left|1_{\mathrm{a}}(j \omega)\right| \leq \overline{\mathrm{l}}_{\mathrm{a}}(\omega)
$$

If the multiplicative uncertainty in equation (2) and (3) is defined as 


$$
1_{m}(j \omega)=\frac{l_{a}(j \omega)}{G_{m}(j \omega) C(j \omega)}
$$

and the bound of multiplicative uncertainty

$$
\bar{l}_{m}(j \omega)=\frac{\bar{l}_{a}(j \omega)}{G_{m}(j \omega) C(j \omega)}
$$

From equation (7) the disk radius (bound of uncertainty) is

$$
\overline{1}_{\mathrm{a}}(\omega)=\left|\mathrm{G}_{\mathrm{m}}(j \omega) \mathrm{C}(\mathrm{j} \omega)\right| \mathrm{l}_{\omega}(\omega)
$$

From the Nyquist stability criterion, let $\mathrm{N}(\mathrm{k}, \mathrm{G}(\mathrm{j} \omega))$ be the net number of clockwise encirclements of a point $(\mathrm{k}, 0)$ of the Nyquist contour. Assume that all plants in the family $\pi$, expresses in equation (4) have the same number (n) of righthand plane (RHP) poles.

There will be robust stability of a specific controller $\mathrm{C}(\mathrm{j} \omega)$ if and only if

$$
\mathrm{N}(-1, \mathrm{G}(\mathrm{j} \omega) \mathrm{C}(\mathrm{j} \omega))=-\mathrm{n} \text { for all } \mathrm{G}(\mathrm{j} \omega) \in \pi
$$

It is also necessary for the nominal plant $G_{m}(j \omega)$ to be stable

$$
\mathrm{N}\left(-1, \mathrm{G}_{\mathrm{m}}(\mathrm{j} \omega) \mathrm{C}(\mathrm{j} \omega)\right)=-\mathrm{n}
$$

From Figure 2 robust stability occurs when the vector magnitude $\left|1+\mathrm{G}_{\mathrm{m}}(\mathrm{j} \omega) \mathrm{C}(\mathrm{j} \omega)\right|$ exceeds the disk radius $\left|\mathrm{G}_{\mathrm{m}}(\mathrm{j} \omega) \mathrm{C}(\mathrm{j} \omega)\right| \overline{1}_{\mathrm{m}}(\omega)$

$$
\left|1+G_{m}(j \omega) C(j \omega)\right|>\left|G_{m}(j \omega) C(j \omega)\right| \overline{1}_{m}(\omega) \text { for all } \omega
$$

Or

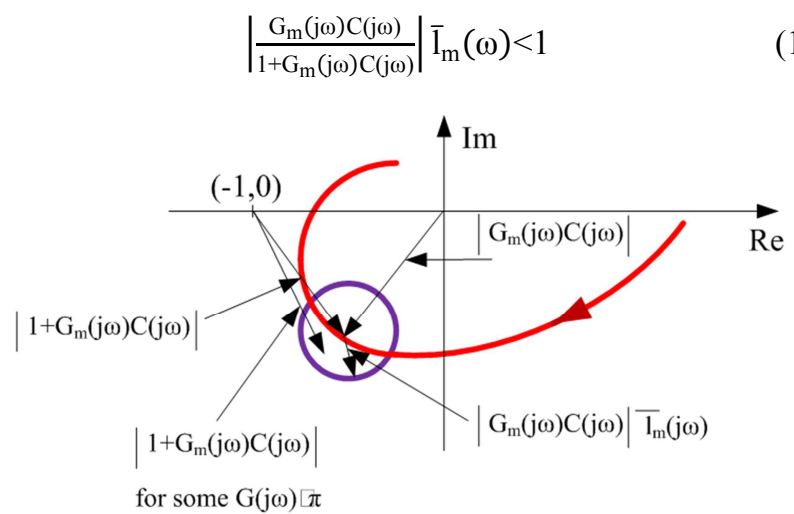

Figure 2. Robust Stability.

A complementary sensitivity function is

$$
T(s)=1-S(s)=\frac{G(s) C(s)}{1+G(s) C(s)}
$$

$$
|1+G(j \omega) C(j \omega)| \geq\left|1+G_{m}(j \omega) C(j \omega)\right|-\left|G_{m}(j \omega) C(j \omega)\right| \overline{1}_{m}(\omega) \text { for all } G(j \omega) \in \pi
$$

Giving

$$
|S(j \omega)|=\left|\frac{1}{1+G(j \omega) C(j \omega)}\right| \leq \frac{\left|S_{m}(j \omega)\right|}{1-\left.\left|T_{m}(j \omega)\right|\right|_{m}(\omega)} \text { for all } G(j \omega) \in \pi
$$

where $S_{m}(j \omega)$ is the sensitivity function for the nominal plant
Equation (12) uses the magnitude of the complementary sensitivity function $\mathrm{T}(\mathrm{j} \omega)$ as defined in equation (13). Thus

$$
|\mathrm{T}(\mathrm{j} \omega)| \overline{1}_{\mathrm{m}}(\omega)<1 \text { for all } \omega
$$

Robust stability can therefore be stated as: "If all plants $\mathrm{G}(\mathrm{s})$ in the family $\pi$ have the same number of RHP poles and that a particular controller $\mathrm{C}(\mathrm{s})$ stabilizes the nominal plant $\mathrm{G}_{\mathrm{m}}(\mathrm{s})$, then the system is robustly stable with the controller $\mathrm{C}(\mathrm{s})$ if and only if the complementary sensitivity function $\mathrm{T}(\mathrm{s})$ for the nominal plant $\mathrm{G}_{\mathrm{m}}$ (s) satisfies the following bound

$$
\left\|\mathrm{T}(\mathrm{j} \omega) \overline{\mathrm{I}}_{\mathrm{m}}(\omega)\right\| \infty=\sup _{\omega}\left|\mathrm{T}(\mathrm{j} \omega) \overline{\mathrm{l}}_{\mathrm{m}}(\omega)\right|<1
$$

where the LHS of equation (15) is the infinity norm of $\mathrm{T}(\mathrm{j} \omega) \overline{1}_{\mathrm{m}}(\omega)$. This means that robust stability imposes a bound on the $\infty$ norm of the complementary sensitivity function $\mathrm{T}(\mathrm{j} \omega)$ weighted by $\overline{\mathrm{l}}_{\mathrm{m}}(\omega)$ '.

\subsection{Robust Performance}

Robust stability provides a minimum requirement in an environment where there is plant model (UAV) uncertainty. For a control system to have robust performance it should be capable of minimizing the error for the worst plant (i.e. the one giving the largest error) in the family $\mathrm{G}(\mathrm{j} \omega) \in \pi$.

$$
\min _{c}\|e(t)\|_{\infty}=\min _{c} \sup _{\omega} \mid S(j \omega)(W(j \omega) \mid
$$

For the $\mathrm{H}_{\infty}$-control problem, from (1), the $\infty$-norm of the weighted sensitivity function can be written

$$
\|S W\|_{\infty}=\sup _{\omega} \mid S(j \omega)(W(j \omega) \mid
$$

If, as part of the design process, a bound is placed upon the sensitivity function

$$
|S(j \omega)|<|W(j \omega)|^{-1}
$$

Should an $\mathrm{H}_{\infty}$ controller be found such that

$$
\|\mathrm{SW}\|_{\infty}<1
$$

then the bound in equation (18) is met. Hence, for robust performance

$$
\|S W\|_{\infty}=\sup _{\omega}|S(j \omega) W(j \omega)|<1 \text { for all } G(j \omega) \in \pi
$$

Form Figure 2 representing robust stability, the actual frequency response $\mathrm{G}(\mathrm{j} \omega) \mathrm{C}(\mathrm{j} \omega)$ will always lie inside the region of uncertainty denoted by the disk, or 
or

$$
\left|T_{m}(j \omega) \bar{l}_{m}(\omega)\right|+\left|S_{m}(j \omega) W(j \omega)\right|<1 \text { for all } \omega
$$

Robust performance then means that the closed-loop system will meet the performance specification given in equation (20) if and only if the nominal system is closed-loop stable (equation (15)) and that the sensitivity function $\mathrm{S}_{\mathrm{m}}(\mathrm{j} \omega)$ and complementary sensitivity function $\mathrm{T}_{\mathrm{m}}(\mathrm{j} \omega)$ for the nominal system satisfy the relationship given in equation (25).

\subsection{Classical Feedback Control System}

The classical feedback control system is shown in Figure 3.

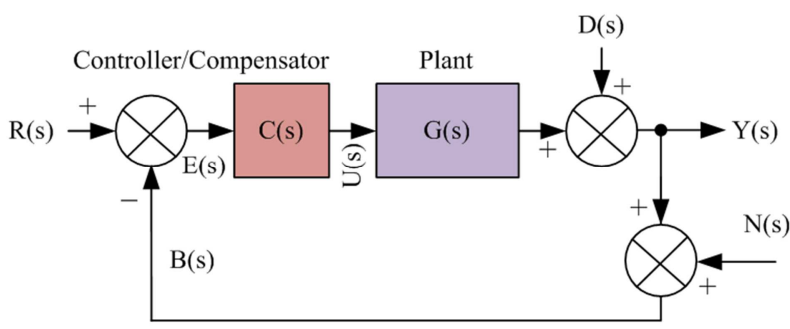

Figure 3. Classical Feedback Control System.

$$
\begin{gathered}
\mathrm{Y}(\mathrm{s})=\mathrm{G}(\mathrm{s}) \mathrm{U}(\mathrm{s})+\mathrm{D}(\mathrm{s}) \\
\mathrm{B}(\mathrm{s})=\mathrm{Y}(\mathrm{s})+\mathrm{N}(\mathrm{s}) \\
\mathrm{U}(\mathrm{s})=\mathrm{C}(\mathrm{s})(\mathrm{R}(\mathrm{s})-\mathrm{B}(\mathrm{s}))
\end{gathered}
$$

Estimating $\mathrm{U}(\mathrm{s})$ and $\mathrm{B}(\mathrm{s})$ from equation (26 to 28 ) gives

$$
\mathrm{Y}(\mathrm{s})=\frac{\mathrm{G}(\mathrm{s}) \mathrm{C}(\mathrm{s}) \mathrm{R}(\mathrm{s})}{1+\mathrm{G}(\mathrm{s}) \mathrm{C}(\mathrm{s})}+\frac{\mathrm{D}(\mathrm{s})}{1+\mathrm{G}(\mathrm{s}) \mathrm{C}(\mathrm{s})}-\frac{\mathrm{G}(\mathrm{s}) \mathrm{C}(\mathrm{s}) \mathrm{N}(\mathrm{s})}{1+\mathrm{G}(\mathrm{s}) \mathrm{C}(\mathrm{s})}
$$

Define a sensitivity function $\mathrm{S}(\mathrm{s})$ that relates $\mathrm{Y}(\mathrm{s})$ and $\mathrm{D}(\mathrm{s})$ when $\mathrm{R}(\mathrm{s})=\mathrm{N}(\mathrm{s})=0$

$$
\frac{\mathrm{Y}}{\mathrm{D}}(\mathrm{s})=\mathrm{S}(\mathrm{s})=\frac{1}{1+\mathrm{G}(\mathrm{s}) \mathrm{C}(\mathrm{s})}
$$

And define a complementary sensitivity function

$$
T(s)=1-S(s)=\frac{G(s) C(s)}{1+G(s) C(s)}
$$

Thus, when $\mathrm{N}(\mathrm{s})=0$, equation (29) may be written

$$
\mathrm{Y}(\mathrm{s})=\mathrm{T}(\mathrm{s}) \mathrm{R}(\mathrm{s})+\mathrm{S}(\mathrm{s}) \mathrm{D}(\mathrm{s})
$$

If $\mathrm{T}(\mathrm{s})=1$ and $\mathrm{S}(\mathrm{s})=0$ there is perfect set-point tracking and disturbance rejection. This requires that $\mathrm{G}(\mathrm{s}) \mathrm{C}(\mathrm{s})$ is strictly proper *has more poles than zeros), so that

$$
\lim _{s \rightarrow \infty} \mathrm{G}(\mathrm{s}) \mathrm{C}(\mathrm{s})=0
$$

However, is $\mathrm{N}(\mathrm{s}) \neq 0$, then equation (29) becomes

$$
\mathrm{Y}(\mathrm{s})=\mathrm{T}(\mathrm{s}) \mathrm{R}(\mathrm{s})+\mathrm{S}(\mathrm{s}) \mathrm{D}(\mathrm{s})-\mathrm{T}(\mathrm{s}) \mathrm{N}(\mathrm{s})
$$

Hence, if $T(s)=1$, there will be both perfect set-point tracking and noise acceptance. Considering the problem in the frequency domain however, it may be possible that at low frequencies $\mathrm{T}(\mathrm{j} \omega) \rightarrow 1$ (good set-point tracking) and at high frequencies $\mathrm{T}(\mathrm{j} \omega) \rightarrow 0$ (good noise rejection).

\subsection{Proposed UAV System}

For the control system shown in Figure 4 procedure the Bode magnitude plots for the sensitivity function $|S(j \omega)|$ and the complementary sensitivity function $|\mathrm{T}(\mathrm{j} \omega)|$ when $\mathrm{K}=10$. For a step input, let $\mathrm{W}(\mathrm{s})=1 . \mathrm{s}$. We have to consider the Bode magnitude plots for $|\mathrm{S}(\mathrm{j} \omega) \mathrm{W}(\mathrm{j} \omega)|$ when $\mathrm{K}=10,50$ and 100 and identify the optimal value using both $\mathrm{H}_{2}$ and $\mathrm{H}_{\infty}$ criteria.

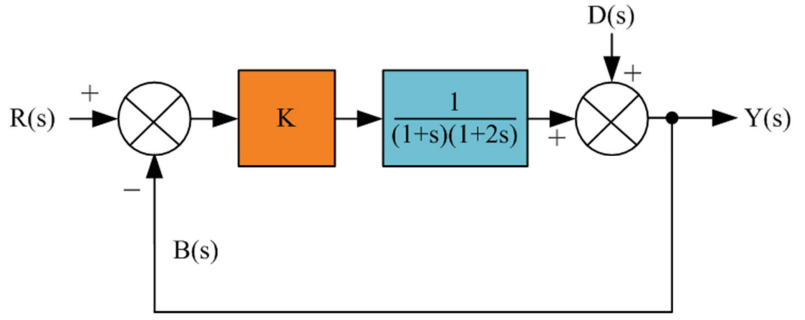

Figure 4. Control System of $U A V$.

\section{Analysis and Discussions}

According to the equation (30),

$$
\mathrm{S}(\mathrm{s})=\frac{1}{1+\mathrm{G}(\mathrm{s}) \mathrm{C}(\mathrm{s})}=\frac{1}{1+\frac{\mathrm{K}}{(1+\mathrm{s})(1+2 \mathrm{~s})}}=\frac{2 \mathrm{~s}^{2}+3 \mathrm{~s}+1}{2 \mathrm{~s}^{2}+3 \mathrm{~s}+(1+\mathrm{K})}
$$

From equation (31),

$$
T(s)=1-S(s)=1-\frac{2 s^{2}+3 s+1}{2 s^{2}+3 s+(1+K)}=\frac{K}{2 s^{2}+3 s+(1+K)}
$$

The Bode magnitude plots for $|S(j \omega)|$ and $|T(j \omega)|$ are shown in Figure 5 for $\mathrm{K}=10$. From Figure 5 it can be seen that up to $1 \mathrm{rad} / \mathrm{s}$, the system has a set-point tracking error of $-0.8 \mathrm{~dB}(|\mathrm{~T}(\mathrm{j} \omega)|)$ and a disturbance rejection of $20 \mathrm{~dB}(|\mathrm{~S}(\mathrm{j} \omega)|)$.

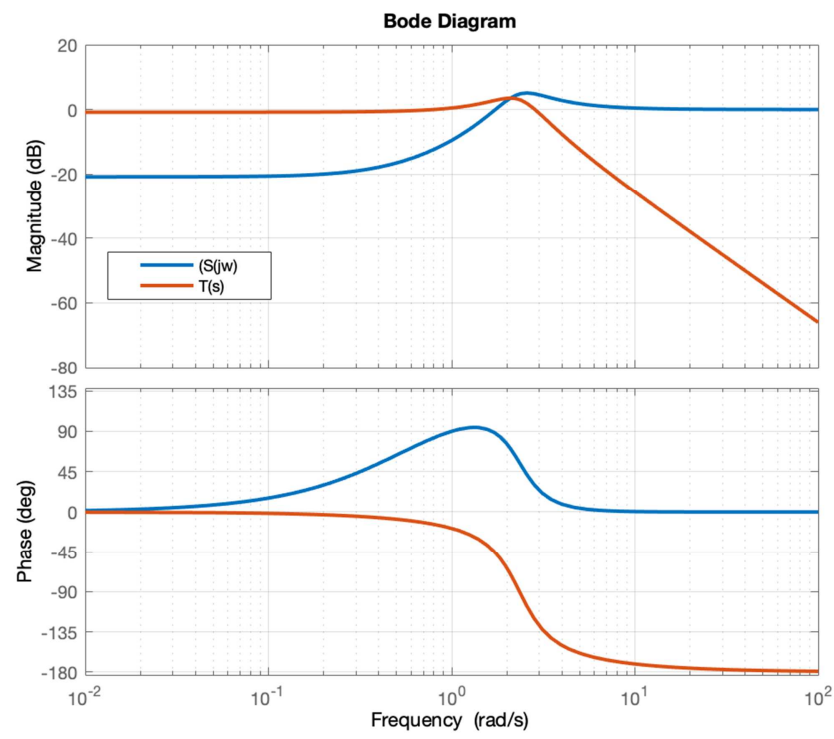

Figure 5. Bode Plot for for $|S(j \omega)|$ and $|T(j \omega)|$. 
For a specific input of a unit step, let $\mathrm{W}(\mathrm{s})=1 \mathrm{rad} / \mathrm{s}$. Hence the weighted sensitivity function is

$$
\mathrm{S}(\mathrm{s}) \mathrm{W}(\mathrm{s})=\frac{2 \mathrm{~s}^{2}+3 \mathrm{~s}+1}{\mathrm{~s}\left\{2 \mathrm{~s}^{2}+3 \mathrm{~s}+(1+\mathrm{K})\right\}}
$$

The Bode plots for $\left|S_{m}(j \omega) W(j \omega)\right|$ for $K=10,50$ and 100 are shown in Figure 6.

From Figure 6 it can be seen that the $\mathrm{H}_{2}$-norm, or average value of the weighted sensitivity function reduces as $\mathrm{K}$ increase and hence, using this criteria, $\mathrm{K}=100$ is the best value. Using the $\mathrm{H}_{\infty}$-norm as defined, the maximum magnitude of the weighted sensitivity function occurs at the lowest frequency. The least upper bound therefore is $0 \mathrm{~dB}$, occurring at $0.01 \mathrm{rad} / \mathrm{s}$ when $\mathrm{K}=100$, so this again is the best value.

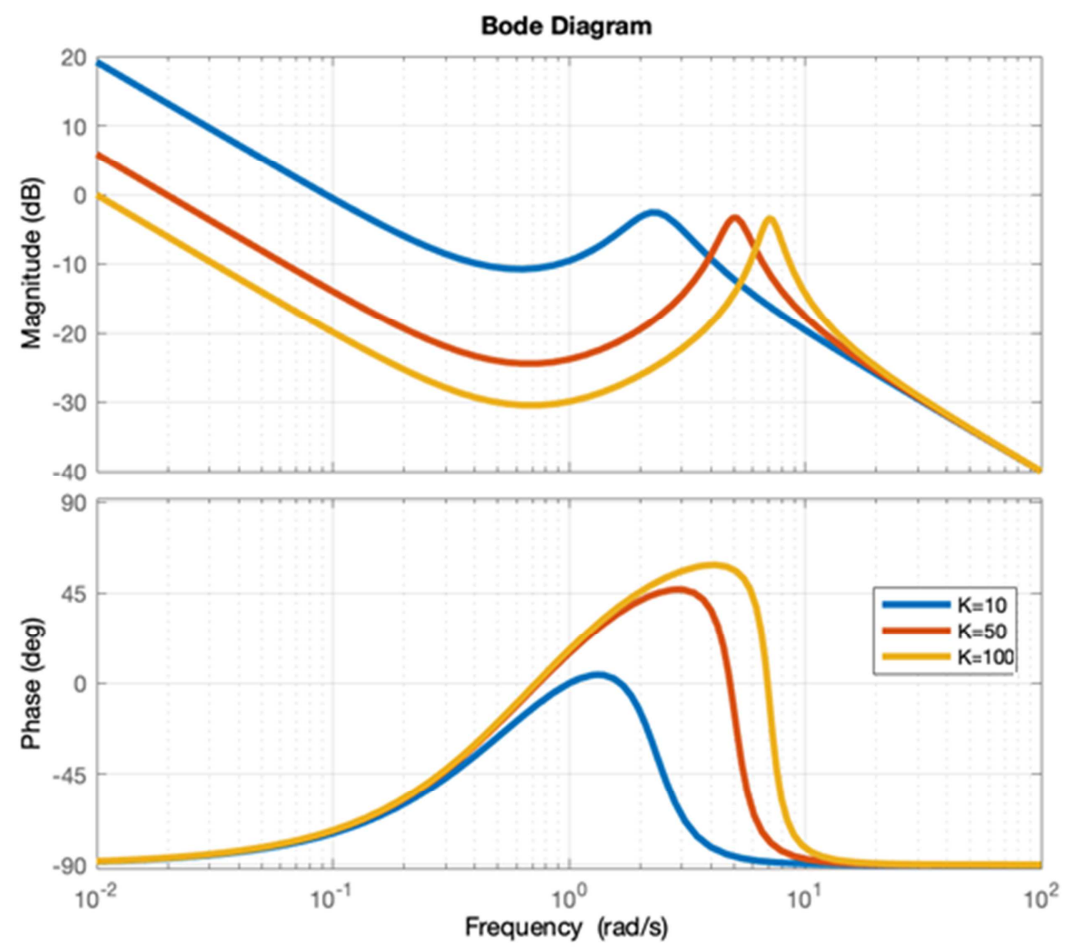

Figure 6. Bode Plot of Weighted Sensitivity Function.

\section{Conclusion}

The paper presents the robust performance analysis on dynamic control of UAV system with the help of Bode plot in MATLAB. The background theory and mathematical model of the dynamic control of robust system for UAV system have been expressed. The objectives of this work have been completed for getting the solution for robust stability problems for dynamic control of unmanned aerial vehicle system which is critical challenge in the space technology.. The specific purpose on analyzing the performance of dynamic of digital control system for space technology was solved based on the robust stability approaches. The best solution for choosing the appropriate gain for stability of digital control system has been done in this works. According to the simulation results, the highest gain could be achieved the best solution for the stability of unmanned aerial vehicle control system.

\section{Acknowledgements}

The author would like to thank many colleagues from the Unmanned Aerial System Laboratory of the Department of
Electronic Engineering of Yangon Technological University to complete this work.

\section{References}

[1] Burns, R. S. (1997) Intelligent Manufacturing, Journal of Aircraft Engineering and Aerospace Technology, MCB University Press, 69 (5), pp. 440-446.

[2] Cadzow, J. A, and Martens, H. R. (1970) Discrete-Time and Computer Control Systems, Prentice-Hall, Inc., Englewood Cliffs, N. J.

[3] Dorato, P. (ed) (1987) Robust Control, IEEE Press, New York.

[4] Dorf, R. C. (1992) Modern Control Systems, 6th ed., AddisonWesley, Reading, Mass.

[5] Frankin, G. F., Powell, J. D. and Workman, M.L. (1990) Digital Control of Dynamic Systems, 2nd ed., AddisonWesley, Menlow Park, CA.

[6] B. Yang; Y. X. Xu ; Q. F. Hu ; B. Yang; C. Y. Xing; X. Rui, Reserch on digital closed-loop control for silicon resonant accelerometer, 2018 25th Saint Petersburg International Conference on Integrated Navigation Systems (ICINS), St. Petersburg, Russia. 
[7] Mingming Yin; Serhiy Bozhko; Taike Yao; Chengxin You, Control System Design and the Power Management of MEFADEC Assembled on More-Electric Aircraft, 2018 IEEE International Conference on Electrical Systems for Aircraft, Railway, Ship Propulsion and Road Vehicles \& International Transportation Electrification Conference (ESARS-ITEC), Nottingham, UK

[8] Nitesh Agrawal; Susovon Samanta, Development of SystemOn-Chip Based Digital Control for Power Converter Application, 2018 IEEE International Conference on Power Electronics, Drives and Energy Systems (PEDES), Chennai, India, India.
[9] Maogui Niu; Yong Zhou; Long Chen; Yanting Han; Yanzhao Mi; Chao Zhang, Research on Servo Control System of Electromechanical Actuators with Compound Control and Three Closed-Loop, 2018 International Conference on Sensing, Diagnostics, Prognostics, and Control (SDPC), Xi'an, China, China.

[10] Jijun Xue; Miao Yu; Xiumei Du; Xiaoying Xu; Jie Fu; Zhiwei Xing, Design and implementation of the control system for magnetorheological suspension of all-terrain vehicle, 2018 Chinese Control And Decision Conference (CCDC), Shenyang, China. 